\title{
MODEL REFERENCE ADAPTIVE CONTROL-BASED GENETIC ALGORITHM DESIGN FOR HEADING SHIP MOTION
}

\author{
NAsir Ahmad Al-Awad \\ University of Mustansiriyah, Faculty of Engineering, Department of Computer Engineering, Palestine Street, \\ 10001 Baghdad, Iraq \\ correspondence: nasir.awad@uomustansiriyah.edu.iq
}

\begin{abstract}
In this paper, the heading control of a large ship is enhanced with a specific end goal, to check the unwanted impact of the waves on the actuator framework. The Nomoto model is investigated to describe the ship's guiding progression. First and second order models are considered here. The viability of the models is examined based on the principal properties of the Nomoto model. Different controllers are proposed, these are Proportional Integral Derivative (PID), Linear Quadratic Regulator (LQR) and Model Reference Adaptive Control Genetic optimization Algorithm (MRAC-GA) for a ship heading control. The results show that the MRAC-GA controller provides the best results to satisfy the design requirements. The Matlab/Simulink tool is utilized to demonstrate the proposed arrangement in the control loop.
\end{abstract}

KEYWORDS: Nomoto ship mathematical models, course changing, ship heading control, PID controller, LQR controller, MRAC-GA controller.

\section{INTRODUCTION}

Automatic control techniques for marine vehicles are proposed to improve their abilities with adequate unflinching quality and economy. The primary reason for the rudder is to control the heading of the ship in course-keeping and course-changing moves [1]. Applying more complex autopilots to deliver guidance is fundamental due to the precision of the execution and mileage [2. A ship in waves is considered as an inflexible body with six degrees of Freedom. Nonlinear numerical models of ship elements are used to reproduce the ship movements, and to outline the closed-loop control frameworks [3]. In order to consider the yaw movement for the ship, the guiding elements can be described by basic linear [4] or nonlinear [5] mathematical model. The ship guiding control frameworks are intended to perform two types of movements: course keeping and course-changing moves, more details are addressed in [6]. There are two necessary methods to approach the mathematical model. First one is classic modelling, which includes the analytical approach. This model is developed based on a physical knowledge of the system, due to the fact of the computational and other practical requirements; the order of the model needs to be reduced for synthesis, evaluation, and implementation of control systems and the second approach is used to simulate ship's movements in real time and it possesses the ability to cope with different shapes of a ship, engines, and sea conditions without the loss of efficiency [7].

The historical backdrop of ship autopilots is over 80 years of age. Minorsky's [8] is one of the early works in the field of programmed control. Sperry [9] presents the main programmed guiding control framework for ships. These controllers are completely mechanical, as they provide a basic controlling activity. The rudder request is relative to the heading error. At the point when PID controllers becomes industrially accessible, they will significantly enhance the execution of the ship behaviour. The primary drawback of the PID is the need of tuning [10]. To overcome the drawbacks of the PID controllers, adaptive controllers are presented [11 13].

Artificial Neural Networks (ANNs) seem to offer a few points of interest over different types of control for ship guides. This is a result of the capacity of neural systems to deal with different framework elements [14]. An ANN controller can be prepared to have good properties of both the consistent parameter controller and the adaptive controller. Fuzzy controllers are effectively employed in ship steering. Fuzzy autopilots, H-infinity autopilots, and LQR controllers have been proposed in different works [15-18. In fuzzy control, it is generally hard to decide and streamline the control rules. It defaults to improve the parameters of a disturbance rejection controller due to many parameters. The backstepping technique can provide a methodical development process for the controller outline, yet it flops in deciding the ideal estimation of the control parameters, as a rule, adaptive fuzzy backstepping control can provide an orderly technique of tackling following or direction control issues, where fuzzy frameworks are utilized to inexact obscure nonlinear functions with obscure parameters [19]. The motivation for this paper is based on the practical need to develop a control system to steer a ship along a reference trajectory defined in a given reference frame. This paper is organized as follows: section 2 depicts the inflexible body elements of the ship in six Degrees of Freedom (6DOF) and 
deliver a movement condition, finally, the scientific model for a payload dispatch including the rudder servo framework is introduced. Section 3 describes the different controllers' methods. The simulation, results, and comparison are addressed in section 4 Section 5 illustrates the main conclusions.

\section{SHIP MATHEMATICAL MODELING}

There are many established ship displaying procedures [20] such as Nomoto model, Norrbin model, Bech Model. All these demonstrating procedures have a distinctive plan stream and methodology. The Nomoto Model is one of the basic linear models that is utilized for displaying ship elements, which underpins each of the 6 degrees of freedom (DOF) and is appropriate for small rudder angles. The Nomoto Model is the most broadly used ship display for autopilot outlines 2123. This model provides a better execution to small rudder angle turnings and best reasonable solution for big boats since it underpins every one of the 6 DOF. The Bech's and Norrbin models are nonlinear models, which are derived from the Nomoto model. These models are used for bigger rudder angles [24]. This section discusses the connection between changes in the heading angle, with respect to the rudder angle. During course changing, it has all the earmarks of being attractive to swing to the new heading with a consistent rate of turn, or potentially with a steady turning span. The new heading must be without overshoot. The likelihood to alter the rate of turn is the main setting required by the user. The full nonlinear model is too intricate to ever be utilized for designing the controller, so the linear model is picked. The principal linear transfer function of a ship directing framework was advanced by Davidson and Schiff [25]. Nomoto et al. 4 have proposed two basic linear mathematical models in light of the model of Davidson and Schiff, Nomoto's models have been utilized broadly by control engineers for an investigation and outline of ship controllers. These models represent a sensibly precise depiction of the directing conduct for a large type of ships. For autopilot applications, there is no compelling reason to incorporate $6 \mathrm{DOFs}$ (three transnational motions surge, sway and heave and the other three rotational motions roll, pitch and yaw)in estimations. For surface vessels, it is ordinary to lessen the model to movement in a surge, sway, and yaw. This is done under the assumption that movements in heave, roll, and pitch are little, see figure 1

The ship control issue is generally taken by applying the classical technique, which considers just two coupled developments, which are yaw and sway [4. The equations below describe the horizontal motion of a well-established ship. These equations can be derived from Newton's laws, after linearizing the equations of the movement, see [4] and [26 28].

In the ship moving issue, just the flat movement is thought about the surge, sway, and yaw movements.
In this way, the equations are 29 :

$$
\begin{gathered}
X=m(u-r v) \\
Y=m(v-r u) \\
N=I_{z} r .
\end{gathered}
$$

where $X, Y$, and $N$ are the surge, sway, and yaw motions, $m$ is the mass of the ship, $I_{z}$ is the moment of inertia to the Z-axis, $(u, v$ and $r)$ are the surge, sway, and yaw speed motion. $\left(u, v, r^{\cdot}\right)$ are surge, sway and yaw acceleration. In considering the steering movement, surge is isolated from steering movement and particularly, by ignoring the swaying movement in Eqs. (2), (3) and by taking the Laplace Transform of yaw and surge with thinking about a consistent speed, a Nomoto second order estimate, which portrays the heading elements of the ship through a basic transfer function, is as [29, 30]:

$$
\frac{r}{\delta}=\frac{K(1+T 3 s)}{(1+T 1 s)(1+T 2 s)}
$$

where $(r)$ is the yaw rate, $(\delta)$ is the rudder angle. $(K)$ is the static ruder gain. (T1,T2, and $T 3)$ are time constants, these parameters rely on working conditions and are generally alluded to as controlling steering movement. In real work, in light of the fact that the pole term $(1+T 2 S)$ and the zero term $(1+T 3 S)$ in Eq. (2) nearly cancel each other out, a further improvement of Eq. (4) should be possible to give the principal arrange Nomoto demonstrate as:

$$
\frac{r}{\delta}=\frac{K}{(1+T s)}
$$

where $T=T 1+T 2-T 3$.

Sometimes called as yaw model, the Nomoto display is legitimate on the assumption, that the ship moves at a steady speed, the propelling push is consistent and the rudder angle is little. Given that conditions are satisfied, the Nomoto display gives a sensibly exact portrayal of course-keeping behaviour [22]. Nomoto model, which is widely employed in autopilot design and yaw dynamics, is characterised by parameters $K$ and $T$ can be determined by manoeuvring tests.

In practice, it is more helpful to work with the heading angle $(\psi)$ than the yaw rate $(r)$, it is ideal to modify Eq. (5) since the yaw rate is actually the time derivative of the ship heading angle, so that:

$$
\frac{\psi}{\delta}=\frac{K}{s(1+T s)}
$$

This model is widely used for the ship autopilot design due to its simplicity and accuracy.

Eq. (6) can be written as state-space form:

$$
\left[\begin{array}{c}
\psi \\
r
\end{array}\right]=\left[\begin{array}{cc}
0 & 1 \\
0 & \frac{-1}{T}
\end{array}\right]\left[\begin{array}{c}
\psi \\
r
\end{array}\right]+\left[\begin{array}{c}
0 \\
\frac{K}{T}
\end{array}\right] \delta
$$




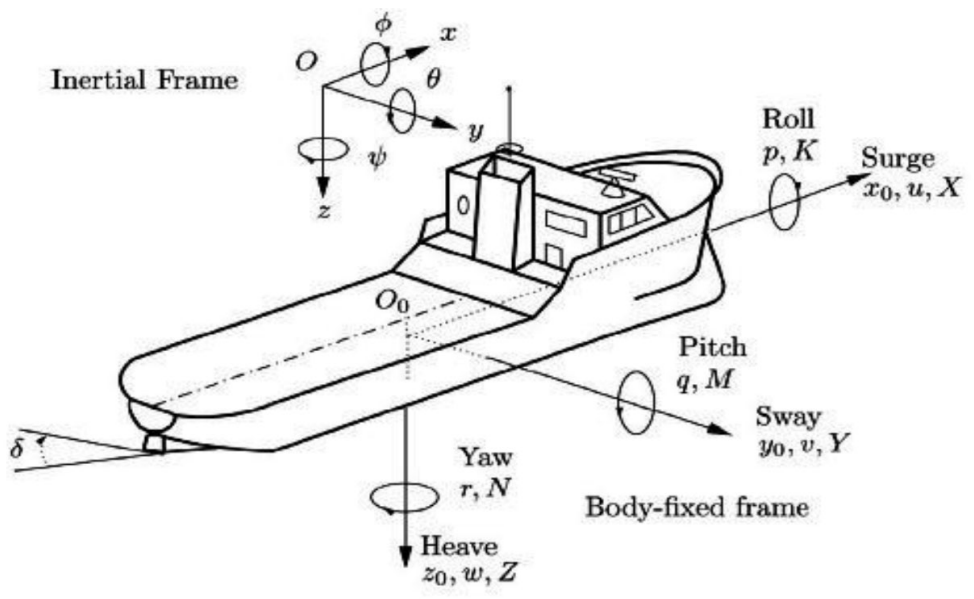

Figure 1. Ship motion description [4].

$$
\begin{aligned}
X & =A x+B u \\
\psi & =\left[\begin{array}{ll}
1 & 0
\end{array}\right]\left[\begin{array}{l}
\psi \\
r
\end{array}\right]+[0] \delta \\
Y & =C x
\end{aligned}
$$

where $r=\frac{d \psi}{d t}$

In other words, Eq. (6) shows that the ship steering autopilot is designed for the heading angle control [30].

Therefore, the Nomoto model might be considered as a linear estimate for the full model ship. If we take $K=0.2803$ and $T=47.44 \mathrm{sec}$ [27], the transfer function of Eq. (6) is:

$$
\frac{\psi}{\delta}=\frac{0.2803}{s(1+47.44 s)}
$$

Figure 2 shows the closed-loop transient response of a ship motion without the controller, it appears that the maximum overshot (the maximum amount by which the response overshoots the steady-state value and is thus the amplitude of the first peak), which is $M p=64.7 \%$ and settling time(defined as the time required by the response to reach and steady within the specified range of $2 \%$ ), which is $T s=342 \mathrm{sec}$. These values are undesirable design requirements for ship movements, therefore, a controller needs to be designed to address this.

\section{SHIP STEERING CONTROL METHOdS}

As a rule, a ship controlling framework is a singleinput-single-output system. This can be seen in figure 3. where $(\psi d)$ is desired heading, $(\psi)$ is the actual heading and $(\delta c)$ is the command rudder angle (all in degrees).

The purpose of a guiding machine is to move the rudder edge to a coveted heading when it is constrained by the control structure, in this paper, it is considered that this machine is a part of the ship model. A controller for a coordination of the ship normally controls the rudder to diminish the error between the reference heading edge and the genuine heading point. For the essential plan, it will, in any case, be expected that the ship's steering flow is linear and of a known order and structure and that there is no disturbance. The objective is to plan the autopilot so the closed-loop framework satisfies the robust stability and design specifications with particular qualities for course-changing issues. There are many types of ship autopilots.

\subsection{PID CONTROLLER}

Minorsky proposed the utilization of a PID controller [8, in 1930. Indeed, even today, most ships utilize this kind of controller. There are few requirements that need to be taken into account in the design [21]:

(1.) For course-changing without oscillations, the damping ratio is chosen between (0.8 and 1)

(2.) The choice of natural frequency $(W n)$ will be limited by the resulting bandwidth of the rudder $W \delta(\mathrm{rad} / \mathrm{sec})$ and the ship's dynamics $1 / T(\mathrm{rad} / \mathrm{sec})$ for a critically damped ship.

The design requirements are, considering no overshot, $(\zeta=1)$ and $W n=0.15 \mathrm{rad} / \mathrm{sec}$. The settling time $(T s=4 / \zeta W n)=39$ sec.

Ref. [23] has inferred straightforward relations for figuring the PD/PID controller parameters for the $(\zeta)$ and $(W n)$ of a closed-loop dispatch control framework. Where

$$
\begin{aligned}
K p & =\frac{T W n^{2}}{K} \\
K d & =\frac{2 T \zeta W n-1}{K} \\
K i & =\frac{W n K p}{K}
\end{aligned}
$$

So that $K p=3.8, K d=47.2$, and $K i=0.057$. Figure 4 shows the closed-loop transient response of a ship motion with a PID controller. The figure demonstrates that the ship does not take after the 


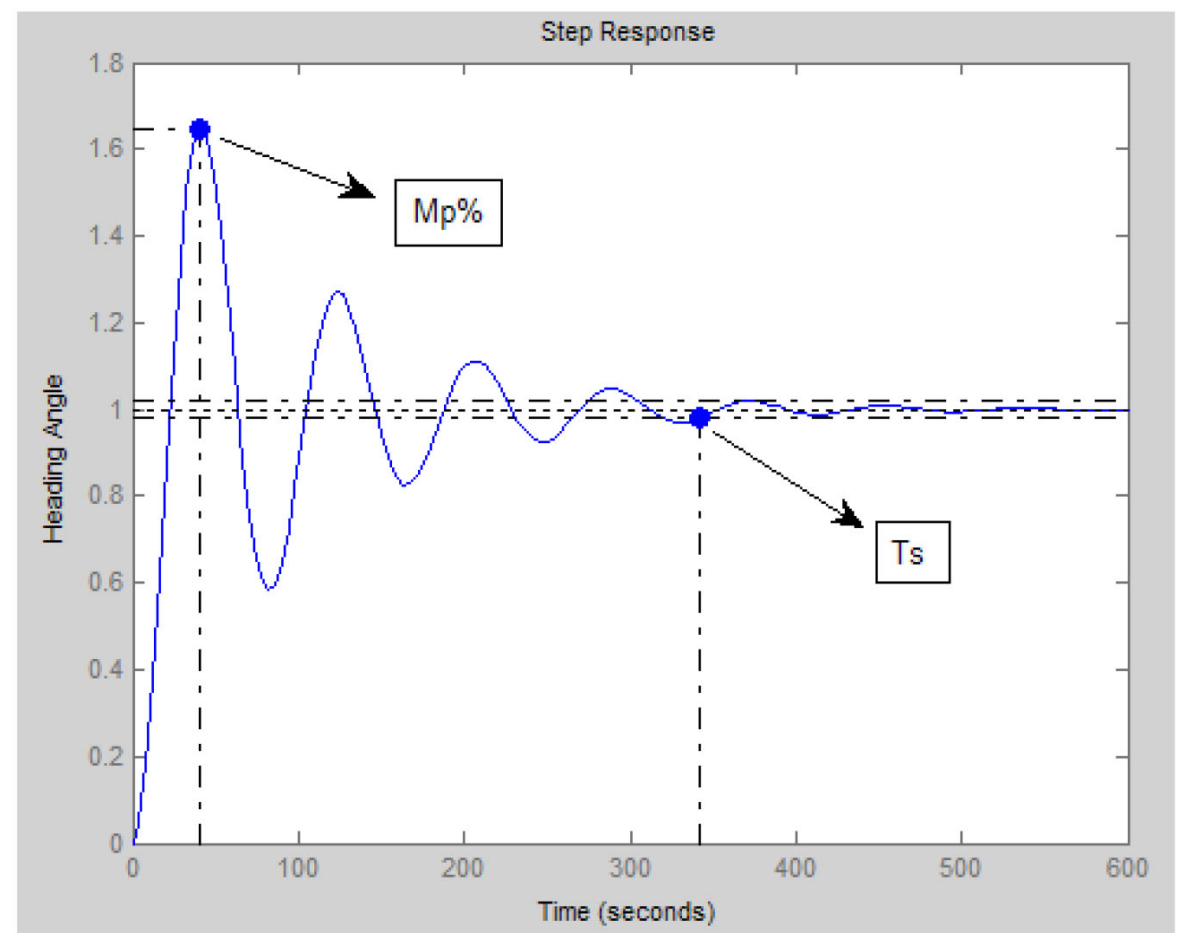

Figure 2. Closed-loop transient response of ship motion without controller.

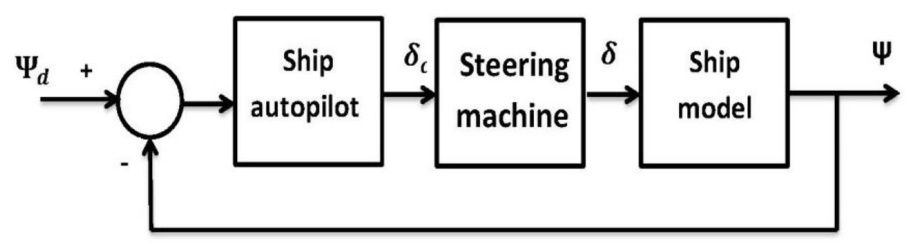

FigURE 3. Ship steering control system.

coveted reaction, an overshoot of about $M p=10.3 \%$ ) can obviously be observed. This can be perilous, if different ships are in the environment or if the ship is cruising in a limited channel. The execution of the controller is not sufficiently accurate, even at a settled forward speed of the ship.

\subsection{LQR CONTROLLER}

An (LQR) can be designed for the state-space model, In order to design a linear optimal control law, the system (A, B, C) must be controllable. Refer to Eq. (7) and (8).

Ref. 31 covers the deduction of the (LQR) and that induction won't be repeated here. In any case, the essential issue is to limit some quadratic cost work $(J)$ obliged by the progression of the framework. Using the MATLAB tool:

$$
\begin{aligned}
& \quad[K, P, E]=\operatorname{lqr}(A, B, Q, R) \text { and let } R=0.1, Q= \\
& c^{\prime} \cdot c .
\end{aligned}
$$

The values of the gain matrix $K=$ [3.1623 33.4766] can be calculated. Figure 5 shows the transient response of the ship motion with (LQR) controller as seen from fig the $(M p=4 \%)$ and $(T s=50.5 \mathrm{sec})$.
This type of controller needs a pre-filter to cancel the offset between the input and the output.

\subsection{MODEL REFERENCE ADAPTIVE CONTROL-BASED GENETIC ALGORITHM (MRAC-GA)}

An adaptive controller is a settled structure controller with movable parameters and a component for naturally altering those parameters. In (MRAC) framework, the desired response is determined by a reference transfer function and the parameters are adjusted in light of the error, which is the contrasts between the yield of the nearby closed-loop framework and the reference demonstrate. The adaptation law provides an adjustment of parameters whose breaking point is the misstep between the plant and the model's yields. Hence the parameters of the controller are balanced so that the mistaken approach is zero. Various adjustment laws have been created. The two essential components are the Gradient and the Lyapunov approach. Here, the Gradient method using the MIT Rule is utilized to build-up the adjustment law 32, 33. To apply the (MRAC), A reference transfer function might be viewed as a pre-filter, see Figure 6. This guarantees 


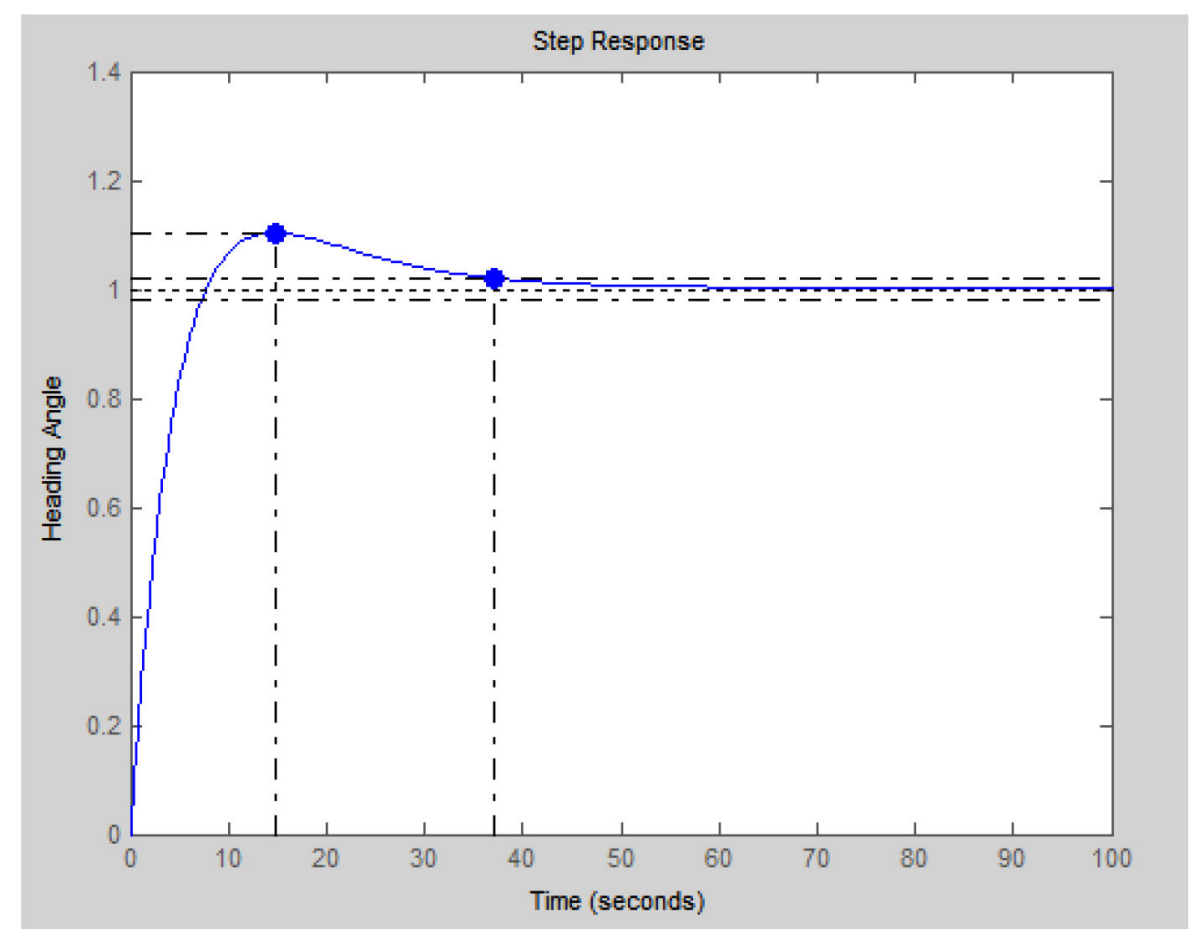

Figure 4. Closed-loop transient response of ship motion with PID controller.

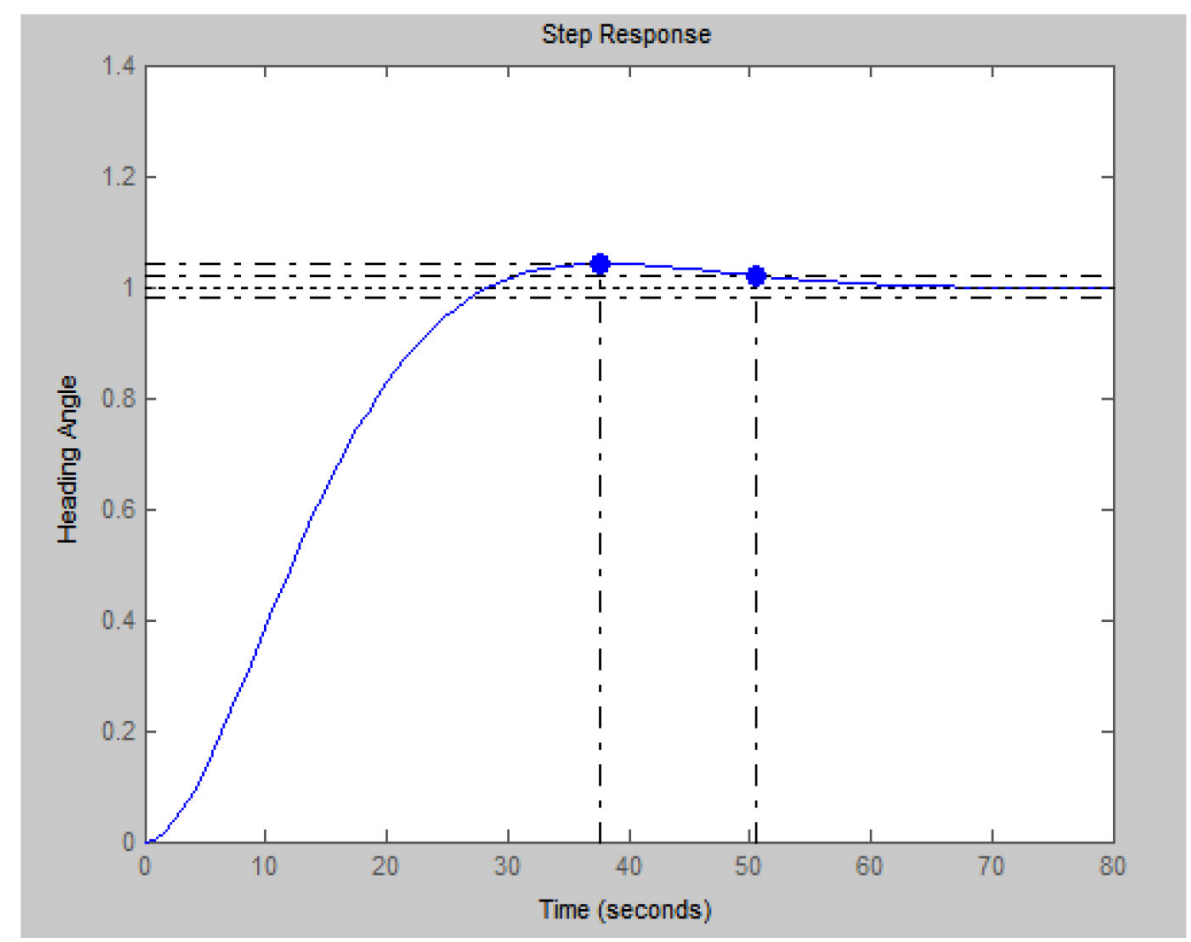

FIGURE 5. Closed-loop transient response of ship motion with (LQR) cotroller. 


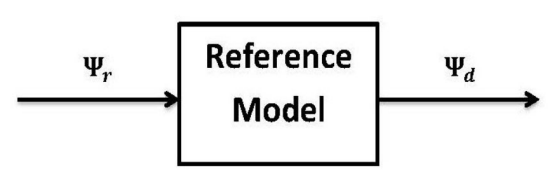

FiguRE 6. The reference model.

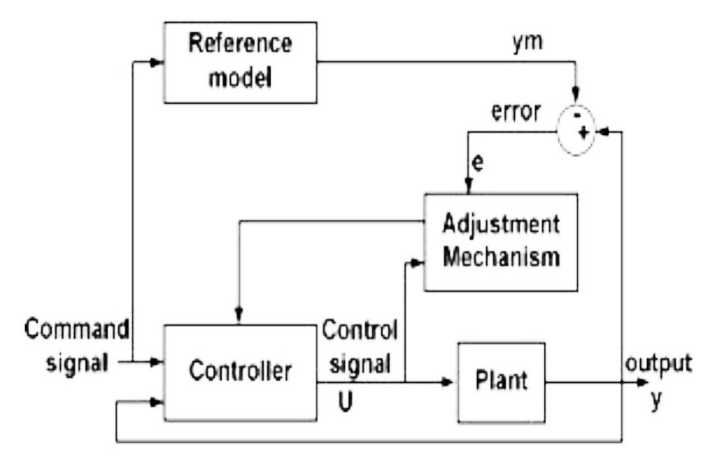

FiguRE 7 . The reference model.

that the numerical challenges related to the input signal are kept away from the calculations [28]. The elements of the reference transfer function ought to be coordinated to the flow of the ship paying little mind to the greatness of the requested change reference yaw point. The reference transfer function is excessively drowsy and cannot create an ideal execution since the ship cannot accomplish the required heading in the base time. Then again, we ought not to utilize a reference model, which is too quick compared to the ship reaction attributes since this may cause a rudder actuator immersion and execution corruption.

To correctly choose a reference model, the following should be considered:

(1.) unified steady-state gain

(2.) speed of response, defined by natural frequency $(W n)$

(3.) damping, specified by the damping coefficient $(\zeta)$

Generally, a second-order transfer function is utilized. Such a model can be depicted numerically as:

$$
\frac{\psi_{d}}{\psi_{r}}=\frac{W n^{2}}{\left(s^{2}+2 \zeta W n+W n^{2}\right)}
$$

\subsection{MIT ADAPTATION LAW}

The MIT law is the first way to deal with the reference versatile control. The name comes from the way that it was produced at the Instrumentation Laboratory (now The Draper Laboratory) at Massachusetts Institute of Technology (MIT), U.S.A., figure 7 shows the MARC block-diagram. To display the MIT law, we will consider a closed-loop structure in which the controller has one versatile parameter.

The desired closed-loop reaction is indicated by a model yield $(y m)$. The error $(e)$ is a contrast between the yield of the framework $(y)$ and the yield of the reference demonstrates $(y m)$. The Modelling error $(e)$ is given by:

$$
e=y-y m
$$

There are many performance indices for control, such as IAE, ISE, ITAE and ITSE, but in this work, we are using the RSS (residual sum of squares).

One approach is to modify parameters such that the cost work $(J)$, as the squared difference of outputs, is:

$$
J(n)=\frac{1}{2} e^{2}=\frac{1}{2}[y(n)-y m(n)]^{2}
$$

To make $(J)$ little, it is sensible to alter the parameters in the course of the negative slope of $(J)$. That is,

$$
\frac{d u}{d t}=-\eta \frac{d e}{d u}
$$

where ( $\eta$ is an adjustable parameter (adaptation gain) and it is used to adjust the convergence speed of the gradient descent optimization method, and $(d e / d u)$ is the sensitivity derivative of the system and indicates how the error $(e)$ is effected by the $(\eta$. By hand calculations, it has been found that the reaction is moderate with the little estimation of adjustment gain. This gain is increased, the settling time decreases and the rise time is diminished. It is extremely hard to check every last estimation of adaptation gain in the Simulink model. With a specific end goal to overcome this issue, a Genetic Algorithm was executed. Genetic Algorithm (G.A) is a heuristic search method used in artificial intelligence for searching through large and complex data sets. The cause of this parameter's iterative pursuit system depends on DARWIN'S "SURVIVAL OF THE FITTEST" guideline 34. GA strategy is motivated by two organic standards to be specific to the procedure of common determination and the mechanics of characteristic hereditary qualities. It controls the gathering of potential arrangements, which is known as the populace. The measure of populace depends on trial and error. For the most part, the projected size of a populace is in a frame from 30 to 100 . The potential arrangement of a populace is called Chromosomes. These are encoded portrayals of the considerable number of parameters of the solution. There are three stages of (G.A), they are Reproduction, crossover, and mutation. The optimization is accomplished in cycle frames called generations and makes another arrangement of chromosomes at every generation through crossover and mutation and the best chromosomes are permitted to the next generation. In this paper, (G.A) parameters are picked by the experimentation strategy as takes:

Populace size $=70 ;$ Crossover rate $=0.2$; Mutation rate $=0.05 ;$ Maximum generation $=100$.

The parameter value of the adaptation gain, which is optimized by using the G.A, is (0.90456).

Figure 8 shows the flow-chart of G.A.

The transient response of the ship motion with (MRAC-GA) controller can be seen from figure 9, it shows the output tracks of the model reference, and 


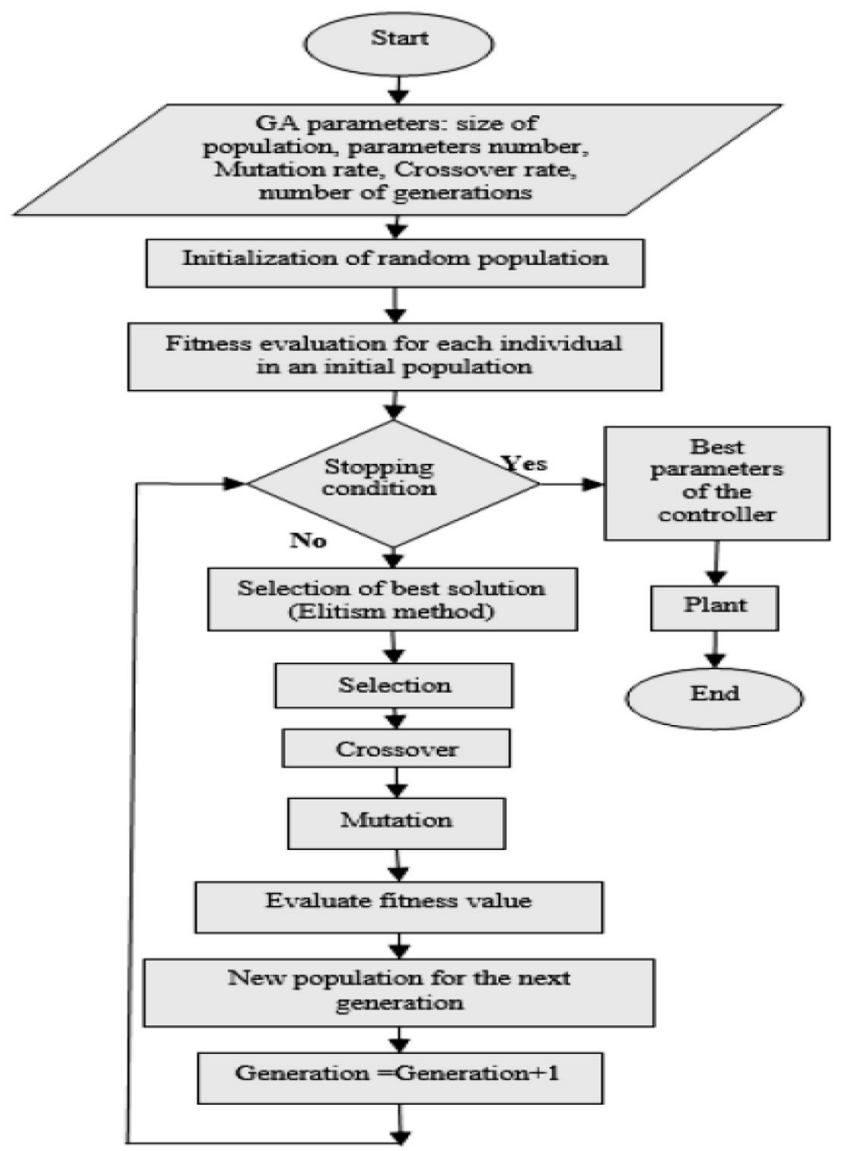

Figure 8. Shows the flow-chart of G.A.

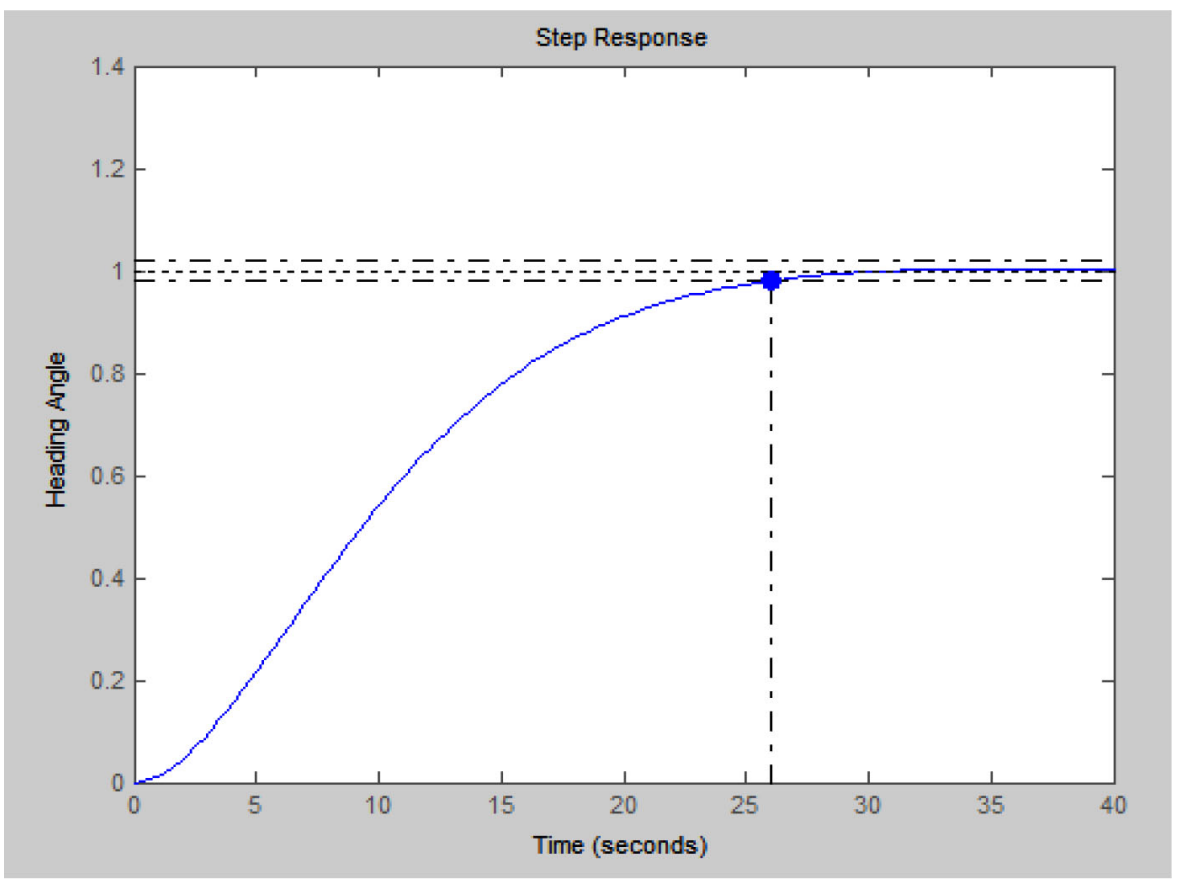

Figure 9. Closed-loop transient response of ship motion with (MRAC-GA) controller for step input. 


\begin{tabular}{lcccc}
\hline Controller type & Settling time (sec) & Rise time (sec) & Max. overshot \% & Steady-state error \\
\hline PID & 37.1 & 5.51 & 10.3 & 0 \\
LQR & 50.4 & 18.4 & 4.12 & 0 (with prefilter) \\
MRAC-GA & 26 & 16.4 & 0 & 0 \\
\hline
\end{tabular}

TABLE 1. Levels of the composite adsorbent preparation variables chosen for this study.

satisfies all the design requirements., $(M p=0 \%)$ and $(T s=26 \mathrm{sec})$.

\section{Discussion}

Different controllers are used to improve the design requirements (settling time, maximum overshoot, and rise time) for a ship moving. In spite of the fact that the PID controllers are generally utilized as a part of the marine control frameworks, their control effectiveness will be tested truly by the framework model uncertainties. In (LQR), there is some overshot, which may endanger a ship on the sea, also, the Ts is out of the design specification. In the comparison of the two (PID, LQR) approaches, the outcomes in the two cases demonstrate that the control power of the proposed technique (MACR-GA) is better than the others, in terms of maximum overshoot $(M p \%)$ and the speed of response, settling time $(T s)$ to reach the steady-state, Table 1 shows the numerical values comparison between all controllers. When comparing the proposed method (MRAC-GA) with the classic controller designs (PID) and (LQR) by using the same model Eq. (6), it is obvious that the design specifications (Max. overshot, settling time, and rise time) have better results for the proposed method.

\section{Conclusions}

This paper shows the response of a framework controlled by a model reference adaptive control method utilizing the MIT scheme, when compared with customary settled pickup controllers (PID) and (LQR), the following was found:

(1.) Adaptive controllers are exceptionally compelling to deal with. The circumstances where the parameter varieties and natural changes are substantial, the results are heavily affected.

(2.) The adaptive controller keeps up a steady powerful execution within the sight of disturbances and immense varieties.

(3.) It is shown that, for suitable values of adaptation gain, the MIT rule can make the transient response of second order model output as close as possible to the adaptive reference model. Also, the response in terms of the settling time, peak time and rise time is reduced with the little estimation of adaptation gain.

(4.) (G.A) is utilized to estimate the adjustment pick up, which requires 9.3245 seconds of computational time to tune the parameter.
(5.) The MRAC-GA is effective in disturbances rejection.

(6.) All design requirements $(M p, T s, T t)$ are satisfied when the MRAC-GA is applied.

\section{ACKNOWLEDGEMENTS}

The author would like to thank Mustansiriyah University (www.uomustansiriyah.edu.iq) Baghdad - Iraq for its support in the present work.

\section{REFERENCES}

[1] T. I. Fossen. Guidance and control of ocean vehicles. John Wiley Sons, New York, 2014.

[2] C.-N. Hwang. The integrated design of fuzzy collision-avoidance and h-infinity autopilots on ships. Journal of Navigation 55(1):117-136, 2002. DOI:10.1017/S0373463301001631.

[3] X.Gu., N.Ma, S.J.Tong, et al. A simplified simulation model for a ship steering in regular waves. In Proceedings of the 12th International Conference on the Stability of Ships and Ocean Vehicles, pp. 14 - 19. 2015.

[4] K. Nomoto, T. Taguchi, K. Honda, S. Hirano. On the steering qualities of ships. Tech. rep., International Shipbuilding Progress, 1957.

[5] R. A. Ibrahim, I. M. Grace. Modeling of ship roll dynamics and its coupling with heave and pitch. Mathematical Problems in Engineering 2010, 2010. DOI:10.1155/2010/934714

[6] T. I. Fossen. Marine control systems: guidance, navigation, and control of ships, rigs and underwater vehicles. Marine Cybernetics, Trondheim, 2002.

[7] S. A. Hariprasad, V. Singh, T. D. Shashikala, K. Shashikala. A design approach to rudder controller. Internation Journal of Computer Science and Technology 3(03):23 - 29, 2012.

[8] N. Minorsky. Automatic steering tests. Journal of the American Society for Naval Engineers 42(2):285 - 310, 1930. DOI:10.1111/j.1559-3584.1930.tb05036.x.

[9] E. Sperry. Automatic steering. Transactions of The Society of Naval Architects and Marine Engineers pp. $53-57,1922$.

[10] A. White, P. Gleeson, M. Karamanoglu. Control of ship capsize in stern quartering seas. International Journal of Simulation 8:20 - 31, 2007.

[11] N. Hovakimyan, C. Cao. L1 Adaptive control theory: guaranteed robustness with fast adaptation. Society for Industrial and Applied Mathematics, Philadelphia, 2010.

[12] Y. Morel, A. Leonessa. Indirect adaptive control of a class of marine vehicles. International Journal of Adaptive Control and Signal Processing 24(4):261 - 274, 2010. DOI:10.1002/acs.1128 
[13] J. Alvarez, I. R. Bertaska, K. von Ellenrieder. Nonlinear Control of an Unmanned Amphibious Vehicle. In Proceeding of the American Society Of Mechanical Engineers, vol. 3 of Dynamic Systems and Control Conference. 2013. DOI:10.1115/DSCC2013-4039

[14] A. Nighat, M. Unar, D. Yaping. Design of heading controller for cargo ship using feedforward artificial neural network. International Journal of Advancements in Computer Technology 5:556 - 566, 2013. DOI:10.4156/ijact.vol5.issue9.66

[15] E. Omerdic, G. N. Roberts, Z. Vukic. A fuzzy track-keeping autopilot for ship steering. Journal of Marine Engineering \& Technology 2(1):23 - 35, 2003. DOI:10.1080/20464177.2003.11020163.

[16] A. A. Ammar. A self-learning fuzzy logic controller for the ship steering system. Iraq Journal Of Electrical and Electronic Engineering 8(1):124 - 139, 2012.

[17] J. Velagic, Z. Vukic, E. Omerdic. Adaptive fuzzy ship autopilot for track-keeping. Control Engineering Practice 11(4):433 - 443, 2003. DOI:10.1016/S0967-0661(02)00009-6

[18] G.Antonio, C. Francisco. Robust design of H-infinity controller for a launch vehicle autopilot against disturbances. Journal of Electrical and Electronics Engineering 11(5):135 - 140, 2016. DOI:10.9790/1676-110502135140.

[19] A. Witkowska, R. Śmierzchalski. Designing a ship course controller by applying the adaptive backstepping method. International Journal of Applied Mathematics and Computer Science 22(4):985 - 997, 2012. DOI:10.2478/v10006-012-0073-y

[20] S. Carrillo, J. Contreras. Obtaining first and second order nomoto models of a fluvial support patrol using identification techniques. Ciencia y tecnología de buques 11(22):19 - 28, 2018. DOI:10.25043/19098642.160

[21] V. Nicolau, C. Miholcă, D. Aiordachioaie, E. Ceangă. $\mathrm{Q} \mathrm{ft}$ autopilot design for robust control of ship course-keeping and course-changing problems. Control Engineering and Applied Informatics 7(1):44 - 56, 2005.

[22] P. Mishra, S. K. Panigrah, S. Dass. Ships steering autopilot design by Nomoto model. International Journal on Mechanical Engineering and Robotic 3(3):37 - 41, 2015.

[23] I. Temiz. An investigation on the ship rudder with a different control system. Electronics And Electrical Engineering 9(105):28 - 32, 2010.
[24] M. Ejaz, M. Chen. Sliding mode control design of a ship steering autopilot with input saturation.

International Journal of Advanced Robotic Systems 14(3):1729881417703568, 2017.

DOI: $10.1177 / 1729881417703568$

[25] R. Skjetne, O. Smogeli, T. Fossen. A nonlinear ship manoeuvering model: Identification and adaptive control with experiments for a model ship. Modeling, Identification and Control 25:3 - 27, 2004. DOI:10.4173/mic.2004.1.1.

[26] S. Das, S. Talole. Robust steering autopilot design for marine surface vessels. IEEE Journal of Oceanic Engineering 41:1 - 10, 2016. DOI:10.1109/JOE.2016.2518256

[27] M. Pande, K. K. Mangrulkar. Design of a heading autopilot for mariner class ship with wave filtering based on a passive observer. International Journal on Mechanical Engineering and Robotics 3(3):30 - 36, 2015.

[28] R. Skjetne, T. I. Fossen, P. V. Kokotović. Robust output maneuvering for a class of nonlinear systems. Automatica 40(3):373 - 383, 2004. DOI:10.1016/j.automatica.2003.10.010

[29] M. Beirami, H. Y. Lee, Y.-H. Yu. Implementation of an auto-steering system for recreational marine crafts using android platform and NMEA network. Journal of the Korean Society of Marine Engineering 39:577 - 585, 2015. DOI:10.5916/jkosme.2015.39.5.577.

[30] M. Tomera. Nonlinear controller design of a ship autopilot. International Journal of Applied Mathematics and Computer Science 20(2):271 - 280, 2010. DOI: $10.2478 / \mathrm{v} 10006-010-0020-8$

[31] H. A. Bouziane, R. B. Bouiadjra, M. B. Debbat. Design of robust lqr control for dc-dc multilevel boost converter. In 4th International Conference on Electrical Engineering (ICEE), pp. 1 - 5. 2015.

[32] P. Jain, M. J. Nigam. Design of a model reference adaptive controller using a modified MIT rule for a second order system. Advance in Electronic and Electrical Engineering 3(4):477 - 484, 2013.

[33] P. Swarnkar, S. Jain, R. K. Nema. Effect of adaptation gain in model reference adaptive controlled second order system. Engineering, Technology $\&$ Applied Science Research 1(3):70 - 75, 2011.

[34] I. Abuiziah, N. Hakarneh. A review of genetic algorithm optimization: operations and applications to water pipeline systems. International Journal of Mathematical and Computational Sciences 7(12):1782 1788, 2013. 